\title{
A REMARKABLE AXOLOTL FROM NORTH DAKOTA.
}

HENRY LESLIE OSBORN.

THE name "axolotl" is primarily the popular designation among the Mexicans for an animal found abundantly in their lakes. The name "siredon" has also been applied to this and allied animals, at first as a generic name, till that was shown to be superfluous by the demonstration of the amblystomid nature of the axolotl, or siredon, larva. The Mexican axolotl is said not to metamorphose from an aquatic to a terrestrial form after the manner of Amblystoma, but to be a permanently aquatic animal, thus imitating Necturus physiologically, with which, however, it has no morphological relationship, as indicated by the fact that Necturus has no free gula folds or opercula, only two gill slits, no dorsal fin, a much shorter tail, and only four toes in the hind limb. It had early been strongly surmised that the axolotls were amblystomas, but Dumeril of Paris in I 865 was the first to observe the metamorphosis of axolotls into true adult amblystomas. Specimens in the Jardin des Plantes laid eggs which in developing did not stop when they reached the form of their axolotl parents, but continued to develop, losing the gills and many other larval features and becoming true terrestrial salamanders. Dumeril's observations were corroborated by Marsh in I868, by Tegetmeyer in London in I 870 , and by Madame Chauvin in I874. The latter managed to arrange an experiment in which young tadpole larvæ were gradually transferred from an aquatic to a terrestrial environment, resulting in the correlated metamorphosis to the terrestrial form:

While Dumeril, Tegetmeyer, Marsh, and Chauvin have shown that an amphibian with the characters of the Mexican axolotl does metamorphose into a salamander under some conditions, it has not been satisfactorily shown as yet that the 
Mexican form does so, for it is contended by Cope ('89) that all of these have been working, not with the Mexican form, or "true axolotl," but with larvæ of Amblystoma tigrimum. The latter have been found in several localities in this country. In I 852 Professor S. F. Baird described the external features of a siredon, called by him Siredon lichenoides, from Santa Fé Creek, New Mexico, and later, in I859, the same writer described another, which he called $S$. gracilis, from the Cascade Mountains, near the fortieth parallel of latitude. This writer did not observe the transformation of siredon (though he conjectured it); but in I 868 Professor O. C. Marsh of Yale College collected siredons in a lảke in Wyoming, at a level of 7000 feet above the sea, and conveyed them to New Haven, where they transformed into A. tigrimum. Tegetmeyer ('70) figures an $S$. mexicanus, which, while in his possession, transformed into an $A$. tigrinum. It appears from his figure to be identical with Baird's S. lichenoides. In all these cases, however, it will be noticed that the siredons were not in their normal surroundings, and hence it is not decided whether their transformation takes place in nature or whether they reproduce while still in possession of the larval characteristics. There is a great difference between merely a greatly overgrown true larva, one not yet capable of reproduction, and the condition of the axolotl in which the reproductive organs are matured before the other organs in the other systems have reached the form that they have in adult amblystomas. It is not impossible that both conditions exist, a siredon in which the animal is a true larva not yet matured, and an axolotl in which the animal is at once a larva and a mature form.

In this sense Marsh's specimens would be siredons, and Dumeril's first generation axolotls, and the second siredons. After the matter of this article had been made nearly ready for the press I had my attention called by Dr. T. G. Lee of the Minnesota State University to a collection of about twentyfive specimens of an axolotl which seems to be very similar to Marsh's S. mavortium, and which were found by him in an alpine lake in Montana. Dr. Lee has most generously placed all of this material (which is splendidly preserved in formalin) 


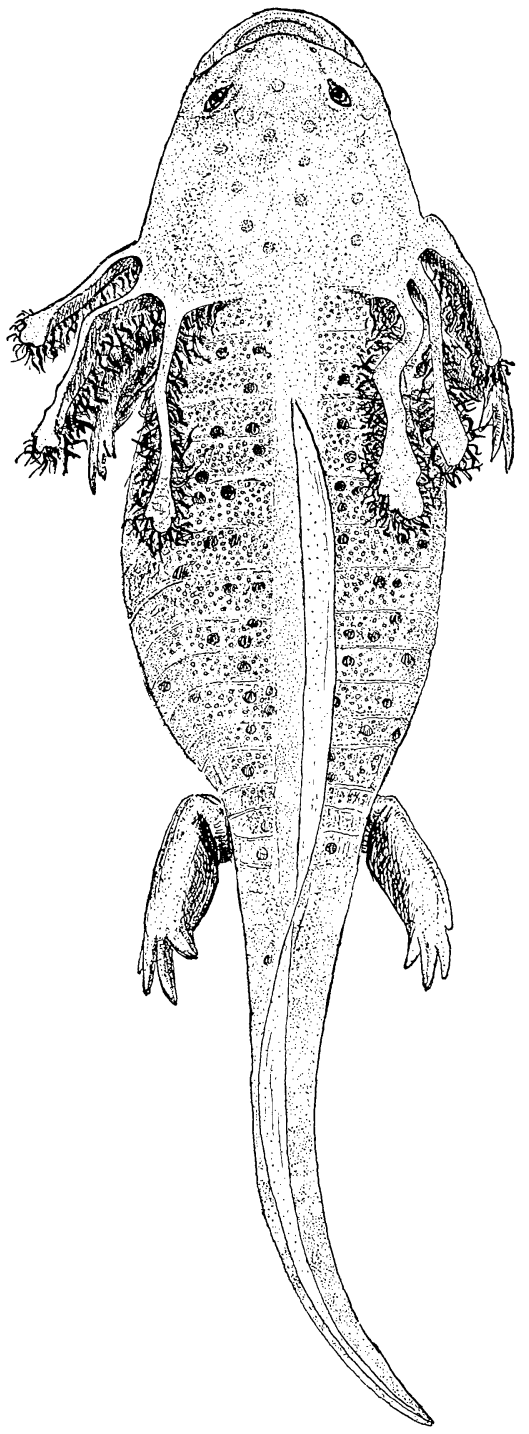

FIG. I.

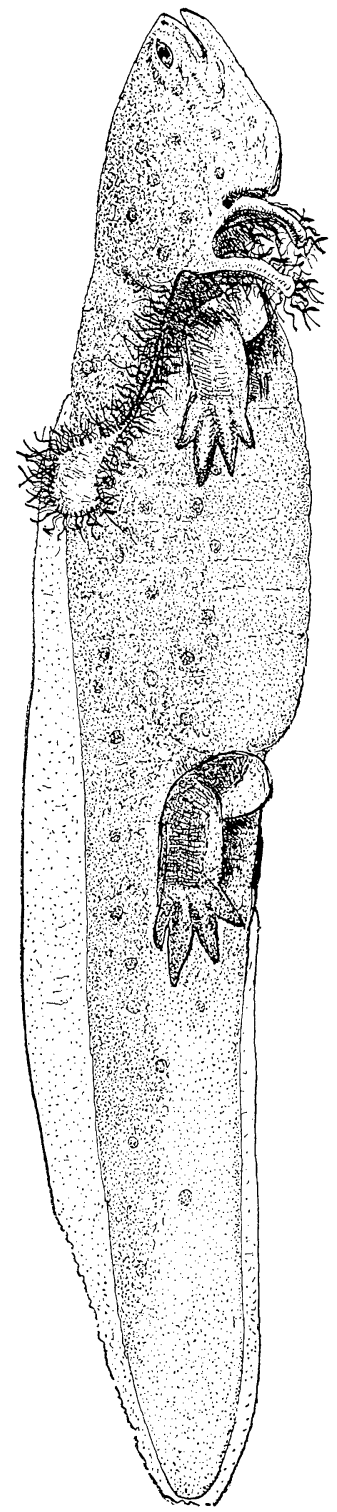

FIG, 2.

Fig. I, - Dorsal view of Dakota axolotl - one-half natural size.

FIG. 2. - View of right side of Dakota axolotl, one-half natural size; the number of toes in the hind limb here is abnormal and should be five.

This content downloaded from 080.082.077.083 on January 19, 2018 06:19:33 AM All use subject to University of Chicago Press Terms and Conditions (http://www.journals.uchicago.edu/t- 
at my disposal, and a survey of its contents shows me that, while it is decidedly unlike the axolotl described in this paper, it is suitable for the study of a number of points in the anatomy of the axolotl, on which at present only the most scanty information is in print. I hope to make this material the subject of a second paper, which will follow this one at a later date. I desire in this connection also to express my obligation to Professor L. Stejneger of the U. S. National Museum, and to Professor H. H. Wilder of Smith College, Northampton, Mass., for their suggestions with reference to the bibliography of this subject.

The Dakota specimen shown in dorsal and side views in Figs. I and 2 differs from previously known forms, including the Montana ones of Dr. Lee, in a number of anatomical points, and besides it comes from a region that is very different in geographical conditions from all regions previously reported.

It is known by only a single specimen, which was sent to the writer for identification by Miss Prudence Tasker of Amenia, North Dakota. It was found on March 21, I899, in Rush River, a tributary of the Red River of the North, a situation described by the sender as "called a river merely by courtesy, - a stream that rises in a marsh and ends in a marsh, - dries up every summer, except in little pools." The stream is mostly shallow, but at one place has been made deeper by a dam, and here the specimen was found. The stream contains limited numbers of the smaller kinds of fish. It was found by a workman who had cut a hole in the ice to water horses, and while baling snow out of the hole baled this specimen out with the snow. He was attracted to it by seeing it crawl. It was taken to the store of Mr. Mosberg in Amenia, where it was examined by many persons, none of whom were familiar with anything like it. It died after a few hours and was sent to me packed in snow, and some drawings and measurements were made while it was still fresh.

Since receiving this specimen another has been reported by Miss Tasker; it was found by Mr. G. Makee in June, I 898, at Kenmare, North Dakota, on the bank of Mouse River, in 
shallow water. This specimen was seen by Miss Tasker and identified as the same as the one herein described. It measured eight inches in length. These specimens, coming as they do from lower levels and not from alpine localities, and from northern, in contrast with the warmer southern levels of most of the former discoveries, are interesting and hold out some prospects that a study of these creatures in their natural surroundings would throw light on the problem of the relationship of these peculiar larvæ to the amblystomas. The general appearance is shown in the accompanying drawings, which were made from the formalin specimen. The following dimensions were also taken from the specimen after preservation in formalin, but both were compared with the data from the fresh animal :

Chin to tip of tail

$312 \mathrm{~mm}$.

" " border of gular fold .

$35 \mathrm{~mm}$.

" " armpit (posteriorly)

$72 \mathrm{~mm}$.

" " center of pelvic arch

I $59 \mathrm{~mm}$.

" " posterior edge of cloaca

$192 \mathrm{~mm}$.

Snout to line joining hinder angle of gills

$59 \mathrm{~mm}$.

Greatest height of tail

$32 \mathrm{~mm}$.

" thickness of tail .

I $8 \mathrm{~mm}$.

" height of dorsal fin

$08 \mathrm{~mm}$.

" diameter of head

$55 \mathrm{~mm}$.

Width of mouth .

$30 \mathrm{~mm}$.

Distance between anterior nares

I $4 \mathrm{~mm}$.

"

“

"6

posterior nares

centers of eyes

Width of head at eyes

Snout to line joining centers of eyes

Length of filament-bearing border of first gill

$\begin{array}{lll}\text { " } & \text { " second gill } \\ \text { " } & \text { " } \text { arm gird gill . } \\ \text { " } & \text { " forearm . } \\ \text { " } & \text { " } \text { hand . . } \\ \text { " } & \text { " thigh . . } \\ \text { " } & \text { " fore leg . } \\ \text { " } & \text { " foot . . }\end{array}$

I $8 \mathrm{~mm}$.

$26 \mathrm{~mm}$.

$39 \mathrm{~mm}$.

I $3 \mathrm{~mm}$.

$45 \mathrm{~mm}$.

$53 \mathrm{~mm}$.

$69 \mathrm{~mm}$.

$24 \mathrm{~mm}$.

I $7 \mathrm{~mm}$.

I9 $\mathrm{mm}$.

I9 $\mathrm{mm}$.

I9 $\mathrm{mm}$.

$22 \mathrm{~mm}$.

The animal displays a combination of larval and adult characteristics in its exterior form. The main lines are those of 
Amblystoma, and many of the proportions are closely similar, and this similarity extends to the internal organs, which are even more like those of the ordinary form of Amblystoma than are the external parts. In point of size it greatly exceeds the average of Amblystoma and goes beyond the maximum reported length by $30 \mathrm{~mm}$. The lengths of fifteen specimens, taken from a collection made at St. Paul, of $A$. tigrinum are as follows: I 22, I 28, I 34, I40, I 5 I, I60, I65, I65, I67, I 7O, I 85, I 87, 200, 204, 220 millimeters. The Dakota specimen is almost $100 \mathrm{~mm}$. longer than the longest of these and much more considerably exceeds their average. Cope ('89) reports a specimen of $250 \mathrm{~mm}$. from Wisconsin, and quotes De Kay for another of $280 \mathrm{~mm}$. The Dakota specimen thus exceeds the recorded maximum length of Amblystoma by over one inch. A special detailed comparison of the dimensions of the separate organs will be made in connection with each of them, and we may pass at once to a survey of them in succession.

There is a considerable difference between the Dakota specimen and the adult amblystomas in the character of the skin, both as to coloration and as to the character of the surface. As to the former point in this axolotl the general color is dark livid blue, with a lighter area in the middle dorsal region, instead of the jet-black color found dorsally everywhere in $A$. tigrinum. On this ground are occasional large circular dark spots. This coloration is in marked contrast with adult $A$. tigrinum, where we find bright yellow spots of a great variety of irregular shapes, often elongate and confluent, and with either S. mexicanum or S. lichenoides. In the former "a pinkish gray ground is covered with numerous small, round, dusky spots rather closely placed " (Cope, '65, '89), and in the latter the ground color is blackish brown, with irregular patches of grayish yellow, "reminding one of the growth of lichens" (Baird and Girard, '52, p. 336), much as in the adult form of A. tigrinum; while in Baird's S. gracilis the body is marked with very small and numerous dark spots that give it a decidedly mottled appearance.

In addition to this difference in coloration the skin of the Dakota form differs from the texture of the adult and, as far 
as I can tell from figures, from that of the other larval forms. It is not smooth, but is somewhat coarse and warty-roughened, generally on the back and sides; but this condition is replaced on either side of the dorsal fin by a narrow area in which the skin is entirely smooth. This difference in texture is noticeable. It is not shown in Baird's figures, but it is possibly indicated in Marsh's, so that it may exist in some stages, at any rate, of their forms.

The head in the Dakota form and in all the siredons is quite different from that of the adult $A$. tigrimum. Dorsally it is flattened as in $A$. tigrinum, but ventrally it is swollen and rounded so as to present in a side view a very different appearance; this difference is directly correlated with the presence of the branchial apparatus. The whole head, however, is relatively larger here (and in the Montana form) than in the adult $A$. tigrinum. The measurement of the length of head is made from the line connecting the posterior bounclary of the gill; the location of this is still visible as a rudiment in the adult, and thus furnishes a very constant point from which to measure. For comparison with this I have taken the distance to the hinder boundary of the cloaca, which gives the length of the trunk, to compare with that of the head, as being more accurate than to take the total length. There is some variation in the sizes of all these regions, and by taking the head and comparing it with the trunk the influence of variation is less than it would be if the two regions of trunk and post-abdomen were both taken.

The length of the head in the Dakota specimen is $3 \mathrm{I}$ per cent of the length of head and trunk together. This is relatively larger than the head of $A$. tigrinum in the larger sizes of the species. Thus it is found in a series of twelve specimens that the length of head ranges from 3 I per cent of head and trunk, in the shortest cases, to 25 per cent in the longest ones. If this ratio were followed out, the length of head for a specimen 3 I $2 \mathrm{~mm}$. in length would be only 20 per cent of head and trunk, in contrast with 3 I per cent as here. This point of size of head shows even more distinctly in Dr. Lee's Montana forms than in this one from Dakota, for there the range is 
between 38 per cent and 30 per cent, in all cases about 5 per cent greater than for adults of A. tigrinum of the same total length. The distance between the centers of the eyes is less than in the adult Amblystoma, where the eyes, instead of being located consiclerably inside of the margin of the face, are lateral. The area of the face, in front of the line connecting the centers of the eyes, is also less than in the adult. In the latter the distance from the snout to this line is generally about one-third of the length of the head, while in the Dakota form it is one-fifth. The diameter of the mouth opening, too, is less than in the adult of $A$. tigrinum, in that the angle of the mouth coincides with the angle of the jaw; in other words, there are no developments of free skin, forming lips or cheeks,

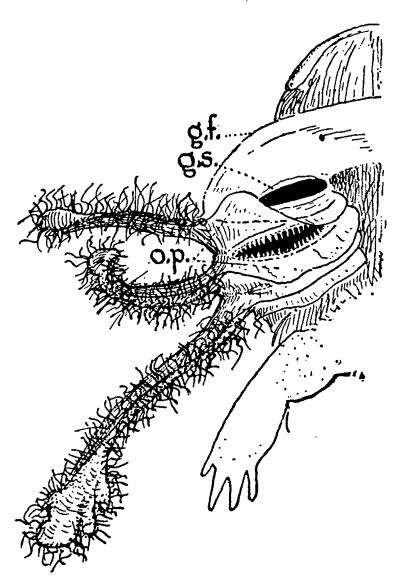

Fig. 3.- Ventral view of throat and jaw of right side of Dakota axolotl, with the gular fold $(g . f$.) turned forward so as to expose the gill slits (g.s.), gill rakers, and four opercula (o.p.). $\times 1 / 2$. and the angle of the mouth is located directly under the eyes; but here, while the angle of the jaws is beneath the eyes, there are folds of skin forming lips and a sort of cheek cavity, so that the angle of the mouth lies anterior to the level of the eyes.

On the under side of the front part of the head there is a transverse fold of skin, "gular fold," which is attached in front and free behind, where it overlaps the gill slits and bases of the gills. This fold is entire in the middle line, as seen in Fig. 3, in contrast with its decidedly emarginate outline, as seen in Baird's figures ('59, Figs. I $d, 2 c$ ) and in the Montana specimens. ${ }^{1}$ The gular fold covers and hides four gill slits. The first one is directly behind it and in front of the first of the four gill arches. It differs from the other three slits by the absence of denticulations of the skin, reinforced by cartilage, and reminding one of the gill rakers of the sturgeon, which guard the passage through the other three slits. The arches are supported by a rod of cartilage which arches around

1 But not in Baird, '52. 
from the hyoid bone to the roof of the skull. The skin below the arches forms a thin flap, the operculum, which is continuous at its outer edge with the gill, a fleshy outgrowth running outward and backward. The gills are compressed at the base so as to be flattened vertically; but this decreases as you pass out on the gill, till at the tip it is flattened from above and considerably widened to a spatulate form. They are of different lengths, increasing as they go back, and the longest is considerably longer than the head. In all other forms they are no longer than the head, and in most they are decidedly shorter. And in all other forms they are lanceolate in outline and taper acutely at the tip.

The gills bear a tangled mass on the under side, or at the margins in the flattened distal part, composed of a great number of jet-black, long, and slender filaments, some of which attain a length of II mm. The filaments are actually much more numerous than is shown in the figures, forming an indiscriminate mass of hairy appearance all down the edge of each gill. These filaments, again, are unlike those of other forms. Thus in S. gracilis of Baird ('59) the filaments are broad, flat, short, and straight; here they are slightly flattened, but are extremely long and slender. In the Montana specimens these structures are more suitably indicated by the term "plates" and are I $\mathrm{mm}$. wide by only $3 \mathrm{~mm}$. long.

The mouth cavity is illustrated in Fig. 4. There are thin, slightly

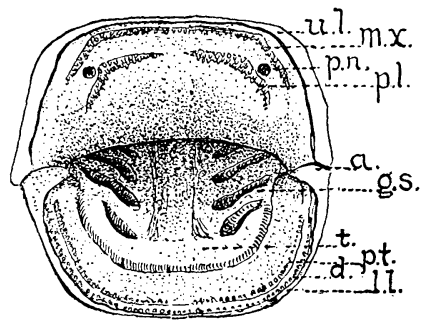

FIG. 4. - Mouth and throat chamber of Dakota axolotl - a., angle of jaws; $d$., dentary ; $s . s$. , gill-arch ; ll., lower lip; $m x .$, maxillary teeth; $p l .$, palatine teeth ; p.n., posterior nares; p.t., posterior row of toeth of lower jaw; u.l., upper lip. $\times 1 / 2$.

fleshy upper and lower lips. Directly behind the upper lip is a bony arch, bearing a limited number of small teeth, $m x$., which are set close together and crowded so as to form, somewhat indefinitely, two rows. This arch is relatively much shorter than it is in the adult $A$. tigrimum, where the row of maxillary teeth reaches back nearly to the angle of the jaw, and very considerably posterior to the level of the posterior 
nares. The palatine teeth are numerous and evident, and there is a decided bend in the palatine bones, in marked contrast with the feebler development of teeth in the adult $A$. tigrimm, where also the palatines are not so strongly bent as here. In the lower jaw the dentary also bears an indistinctly double row of well-marked teeth, and directly behind it there is another row of teeth (splenial ?), carried on a bony or cartilaginous support, which appears to be entirely distinct from the dentary, though in close relation with it. The posterior row is not complete in the middle line. The floor of the mouth is pierced by the gill slits, and the tongue is only feebly developed.

The trunk region is somewhat distended by the reproductive organs. Its wall is marked by the "costal grooves," as they are called by Cope ('89), consisting of light, narrow myocommata and darker broad myomeres. The number of myomeres included between the front and hind limbs is twelve, as in A.tigrimum. The proportion of the trunk to the post-abdomen is the same as in the adult A. tigrinum. The dorsal fin originates on the level of the second costal ring, some distance behind the head. The position of this point of origin in the Mexican axolotl and in Baird's siredons, as indicated in the figure in Stansbury's report, is close to the head, but in Tegetmeyer's figure and in the specimens from Montana the fin originates as in the Dakota specimen. The fin is not very high at any point, and in texture is not thin; in the Montana specimens the fin broadens out very much in the post-abdominal region, more so than in any other recorded forms, and is very thin, so that the branchings of the blood vessels are very evident.

The limbs are located here as usual, but the fore limb is shorter than in some of the allied forms, reaching only to the sixth myomere, while in the Montana axolotls I find that they reach the eighth myomere. The fingers are considerably flattened, and at their base the skin stretches across between them so as to produce a web; this result is further aided by the very broad and slightly flattened condition of the forearm. The same condition is noticeable in the hind limb. In the latter the typical number of toes, viz., five, is found on the left side, but only four are present on the right; this number is abnormal. 
The "tail," or post-abdomen, is compressed, and it is considerably less in cross-section than the trunk; this disparity is greater here than in adults. Its outline is unlike that of other axolotls and of the adult $A$. tigrimum; in them it gently tapers from the base; here it is almost parallel-sicled till the tip is nearly reached, when the taper is rapid. In this point the tail is decidedly different from the Montana forms.

A complete dissection of the viscera has not been made, but enough has been seen by cutting through the body wall.and pushing the parts aside to show that the organs generally are as in the adult salamander. This was seen to be true of the alimentary organs, the lungs, and the urogenital system. The lungs are fully developed on both sides. The specimen is a female, and the ovaries are fully ripe and contain the usual vast number of eggs, each having a diameter of about $2 \mathrm{~mm}$. The oviducts are greatly twisted and dilated with albuminous material to be used in egg laying. These organs both agree in appearance with adult females of $A$. tigrimum, ready for spawning, which have been often met in the laboratory. The maturity of these organs and the simultaneous larval condition of so many other parts are convincing proof that the specimen is a true axolotl. It is not credible that the animal could have undergone transformation of its other parts before the eggs should have been laid.

The spawning season for Amblystoma is very early in the spring; often the spawn is found in the ponds while they are still frozen in places, and this specimen caught in the last of March was just in readiness for the spawning act. It is interesting to note here that some of the specimens from Montana are also in a condition of activity of the reproductive organs, as is shown by the recognition of Spermatozoa in the males, and ripe ova in the females. These facts are the only ones on record, so far as I am aware, going to prove that the American forms are like the Mexican axolotl, and in their native state reproduce while still larval in form.

Since this specimen is the only one of which we have any knowledge, it seems premature to speculate on its significance in connection with the axolotl question, and I have 
intended at present only to record the facts about it. These, in brief, are a close general resemblance to A. tigrimum; a decided unlikeness to the hitherto recorded siredon larva of that species in the following particulars: the total size of the specimen, the shape of the gular fold, the size and shape of the gills, the number, size, and shape of the gill filaments; the proximity of the eyes to the snout, the coloration of the body, the length of the front limbs, the outline of the post-abdomen, the locality in which it is found. This decided divergence calls for a more complete study of the Amblystomidæe of that region, and this it is hoped will be made during the coming season.

Biological Laboratory, Hamline University,

St. Paul, Minn., Feb. 3, I900.

\section{BIBLIOGRAPHY.}

'52 Baird, S. F. Proc. Phil. Acal. Vol. vi, p. 68.

'52 BaIRD, S. F., and GIRARD, C. App. C, Reptiles, Stansbury's Expedition, p. 335, Fig. I, Pl. I.

'59 Baird, S. F. Rep: U. P. R. R. Survey. Vol. x, Fig. 2, Pl. XLIV.

'75 Chauvin, Marie von. Zeitschr.f. wiss. Zool. Vol. xxv, p. 297.

'65 Cope, E. D. Proc. Phil. Acad. Series 2, No. 2, p. 197.

'89 Cope, E. D. The Batrachia of North America. Bull. U. S. Nat. Mus. No. 34, p. 70.

Cunningham, J. T. Siredon. Encycl. Brit. Vol. xxii, p. 96.

Cuvier, G. Règne Animal. Fig. 2, 2 a, Pl. XLI.

'65 Dumeril, A. Compt. Rend. Vol. 1x., p. 756.

'97 Hertwig, R. Lehrbuch der Zoologie. P. 29, Fig. 5.

Huxley, T. H. Amphibia. Encycl. Brit. Vol. i, p. 763, Figs. I 5-I 8 .

'68 Marsh, O. C. Amer. Journ. Sci. Series 2, vol. xlvi, p. 364, figure and plate.

75 Weismann, August. Zeitschr.f. wiss. Zool. Bd. xxv. 